\title{
Ações de sustentabilidade ambiental adotadas pelo sistema de bibliotecas da UFU
}

\author{
Environmental sustainability actions in UFU's Library System
}

\author{
Kelma Patrícia Souza' $(*)$ \\ Patrícia Oliveira Portela ${ }^{2}$ \\ Eunir Augusto Reis Gonzaga ${ }^{3}$
}

\section{Resumo}

Entendendo a sustentabilidade como a harmonia entre o desenvolvimento econômico e a preservação ambiental, este trabalho justifica-se por descrever as ações de sustentabilidade desenvolvidas no Sistema de Bibliotecas da Universidade Federal de Uberlândia (SISBI/ UFU). Foi desenvolvido um levantamento das ações de sustentabilidade promovidas pelas bibliotecas em todos os Campi da UFU, com o objetivo de identificar os impactos no comportamento dos indivíduos que frequentam seus espaços físicos. Trata-se de um estudo de abordagem qualitativa, agregado a recursos da abordagem quantitativa, de natureza aplicada e viés descritivo a partir de levantamento bibliográfico, análise de documentos internos, descrição das ações promovidas, consulta a servidores do SISBI/ UFU e da Diretoria de Sustentabilidade (DIRSU/UFU). Esperamos que este trabalho contribua para inspirar outras bibliotecas a adotarem ações de sustentabilidade, bem como que o SISBI/UFU dê continuidade às ações já adotadas e implemente novos projetos que promovam o desenvolvimento sustentável.

Palavras-chave: Bibliotecas sustentáveis. Consumo sustentável. Bibliotecas Gestão ambiental.

\section{Abstract}

Considering sustainability as the harmony between economic development and environmental preservation aiming to minimize world poverty, this work is justified by presenting the description of the actions developed at Federal University of Uberlandia's Library System (SISBI/UFU) and the analysis of the impact promoted favoring sustainable development. A survey of sustainability actions promoted by all UFU's campuses libraries was developed aiming to identify the impacts on the behavior of individuals who attend its physical spaces. This is a qualitative study, assembled to qualitative approach resources, of applied nature and descriptive feature based on bibliographic survey, internal documents analysis, promoted actions description,

1 Bibliotecária - Sistema de Bibliotecas da Universidade Federal de Uberlândia - Uberlândia/MG; Doutoranda em Geografia - Universidade Federal de Uberlândia; Mestre em Ciências Ambientais - Universidade Brasil - Campus Fernandópolis/SP; E-mail: kelma.biblio@gmail.com $\left(^{*}\right)$ Autor para correspondências

2 Bibliotecária do Setor de Referência da Biblioteca Central Santa Mônica do Sistema de Bibliotecas da Universidade Federal de Uberlândia - Uberlândia/MG; Mestre em Ciências Ambientais pela Universidade Brasil, campus de Fernandópolis, SP; E-mail: patriciap@ufu.br

3 Geógrafo; Prefeitura Universitária da Universidade Federal de Uberlândia - Uberlândia/MG; Doutorando em Geografia Universidade Federal de Uberlândia; Mestre em Qualidade Ambiental - Universidade Federal de Uberlândia; Experiência em Coordenação de Planejamento Ambiental, com atuação na área de Ciências Ambientais; E-mail: euniraugusto@ gmail.com

Recebido para publicação em 06/02/2017 e aceito em 16/04/2019

\begin{tabular}{llllll}
\hline Ambiência Guarapuava (PR) v.l5 n.I & p. $146-160 \quad$ Jan/Abr 2019 & ISSN I808 - 025I
\end{tabular}


consulting SISBI/UFU servers and UFU Sustainability Directorate. We hope this work will help inspire other libraries to adopt sustainability actions, and that SISBI / UFU will continue to embrace the actions already taken and will implement new projects that promote sustainable development.

Keywords: Sustainable libraries. Sustainable consumption. Libraries Environmental Management.

\section{Introdução}

O Sistema de Bibliotecas da Universidade Federal de Uberlândia (SISBI/UFU), criado em 1989, com área física total de $11.675,70 \mathrm{~m}^{2}$, é composto por oito ${ }^{1}$ bibliotecas, com acervos constituídos de obras das áreas referentes aos cursos oferecidos nos Campi onde estão localizadas, atendendo às comunidades internas e da região:

a) Biblioteca Central Santa Mônica (Uberlândia,MG): centraliza a administração do SISBI/ UFU e as atividades de seleção, aquisição, catalogação e classificação do material informacional de todas as bibliotecas;

b) Biblioteca Setorial Umuarama (Uberlândia, MG);

c) Biblioteca Setorial Educação Física (Uberlândia, MG);

d) Biblioteca Setorial de Educação Básica (Uberlândia, MG);

e) Biblioteca Setorial Hospital das Clínicas (Uberlândia, MG);

f) Biblioteca Setorial Ituiutaba (Ituiutaba, MG); Biblioteca Setorial Monte Carmelo (Monte Carmelo, MG);

g) Biblioteca Setorial Patos de Minas (Patos de Minas, MG).

As bibliotecas da UFU oferecem uma estrutura diversificada para atender as demandas da comunidade universitária e também da comunidade externa. A estrutura pode ser dividida entre física e informacional.

A estrutura física é composta por espaços para serviços técnicos ${ }^{2}$ e administrativos ${ }^{3}$, guardavolumes, acervo $^{4}$, área e cabines para estudos, sendo estes em grupo ou individual, ilhas de pesquisa, hall para exposições, sala para utilização de materiais audiovisuais, salas contendo equipamentos de autodevolução, ambiente para acesso à internet por meio de rede cabeada, ambientes para acervos especiais $^{5}$, estudo $24 \mathrm{~h}$, sala para treinamentos, anfiteatro e atendimento aos usuários.

A estrutura informacional compreende o acesso à informação, disponível em diversos formatos e suportes. A informação impressa ainda é a forma mais utilizada, considerando a indisponibilidade no formato eletrônico de algumas obras das bibliografias básicas e complementares dos cursos de graduação, bem como a necessidade de concentrar o maior investimento na aquisição de material impresso para atender as exigências do instrumento de

I Está prevista a criação da nona biblioteca em 2017, que será a Biblioteca Setorial Glória.

2 Seleção e aquisição de material informacional, catalogação e classificação, baixa e remanejamento do acervo, restauração, circulação do material informacional e suporte técnico em informática.

3 Secretaria, apoio administrativo, assessoria de informatização, coordenação de atendimento ao usuário e assessoria de planejamento.

4 Livros, periódicos, partituras, CDs, DVDs, VHS, normas técnicas, teses e dissertações, audiolivros, conjunto de peças, fitas cassete e discos de vinil.

5 Coleção Especial Jacy de Assis, Coleção Especial Aricy Curvello, Coleção Especial Yan Michalski, Coleção Especial Antonio Mercado Neto, Coleção Especial Litto, Coleção Especial Jodacil Damaceno, Coleção Especial Dr. Kerr, Coleção Especial Homero Santos, Coleção Especial Hélio Benício, Coleção Especial Agropecuária, Coleção Especial Memória UFU, Coleção Especial Textos e Cartazes de Teatro, Coleção Especial de Arte e Coleção Especial de Obras Raras. 
avaliação de cursos de graduação: presencial e à distância ${ }^{6}$ do Instituto Nacional de Estudos e Pesquisas Educacionais Anísio Teixeira (INEP), do Ministério da Educação (MEC), onde o mesmo utiliza como critério de análise para que o curso obtenha conceito máximo, que trata-se da nota 5, no indicador de bibliografia básica:

Quando o acervo da bibliografia básica, com no mínimo três títulos por unidade curricular, está disponível na proporção média de um exemplar para menos de 5 vagas anuais pretendidas/ autorizadas, de cada uma das unidades curriculares, de todos os cursos que efetivamente utilizam o acervo, além de estar informatizado e tombado junto ao patrimônio da IES. (BRASIL, 2015).

O Sistema de Bibliotecas (SISBI/UFU) é um grande gerador de resíduos produzidos de várias maneiras, tais como descarte de material informacional desatualizado e danificado, cópias de documentos para consulta por usuários e funcionários, além de sedimentos oriundos das rotinas de trabalho, de vivência e sobrevivência das pessoas, como restos de alimentos, produtos e materiais de higiene e limpeza, entre outros.

Nesse sentido, o SISBI/UFU vem implementando, desde 2011, ações extensionistas com o intuito de promover o desenvolvimento sustentável nas atividades acadêmicas e administrativas, em seu espaço físico, conforme sua visão atual:

Ser referência regional, nacional e internacional na gestão da informação e do conhecimento, com padrão de excelência no atendimento às necessidades da Universidade Federal de Uberlândia, na valorização das relações humanas e na promoção do desenvolvimento sustentável e tecnológico. (UNIVERSIDADE FEDERAL DE UBERLÂNDIA, 2016).

Dentre os objetivos dos projetos, discutiu-se prioritariamente, a redução de custos e o uso racional de recursos naturais a partir de materiais de educomunicação ambiental.

Entendendo a sustentabilidade como a harmonia entre o desenvolvimento econômico e a preservação ambiental, e visando minimizar a pobreza do mundo, este trabalho justifica-se por descrever as ações desenvolvidas no SISBI/UFU e analisar o impacto promovido em prol do desenvolvimento sustentável.

Sabe-se que as discussões em torno dos problemas ambientais intensificaram-se nas últimas décadas, devido à inquietação da sociedade contemporânea com o desenvolvimento insustentável. De acordo com Silva e outros (2015), essas discussões são fortalecidas pela divulgação e publicação de pesquisas que tragam informações sobre a preservação do Meio Ambiente.

$\mathrm{Na}$ busca por melhores condições de vida, a sociedade tem passado por transformações, as quais têm possibilitado uma série de conquistas tecnológicas, permitindo uma exploração cada vez mais intensa dos recursos naturais. Mas, junto com isso, vieram também problemas de diversas ordens, dentre eles os de cunho ambiental, que têm sido agravados com a ampliação do poder de consumo das diferentes classes sociais. (PEREIRA, 2014, p. 576).

Partindo desse contexto, o presente trabalho se propõe a desenvolver um levantamento das ações de sustentabilidade promovidas pelas bibliotecas em todos os Campi da UFU, com o objetivo de identificar os impactos no comportamento dos indivíduos que frequentam seus espaços físicos.

6 Cf.http://download.inep.gov.br/educacao_superior/avaliacao_cursos_graduacao/instrumentos/2015/ instrumento_cursos_graduacao_publicacao_agosto_2015.pdf 


\section{Consumo responsável para a Universidade}

Sabe-se que os impactos do uso descontrolado dos recursos naturais pelo ser humano estão ocasionando alterações no ambiente natural e, em um futuro próximo, poderão comprometer totalmente a viabilidade da vida em nosso planeta (BRUM; HILLIG, 2010). Paralelamente, podese perguntar até que ponto as próprias regras que os indivíduos têm como consumidores e que foram estabelecidas ao longo de sua história de aprendizagem regulam, mesmo que parcialmente, suas compras no contexto organizacional (COUTO; COELHO, 2015).

A globalização permitiu que o acesso às informações tornasse as crises social e cultural perceptíveis em lugares do planeta que nunca tinham sido considerados significativos, tanto economicamente quanto geograficamente. $\mathrm{O}$ homem adotou um ritmo de vida alucinante e nada saudável para a preservação da vida no planeta Terra, onde a falta de perspectivas, num curto prazo, poderá impulsionar a humanidade em busca de soluções, que permitirão convívio harmonioso, justo, equilibrado para todas as formas de vida, incluindo suas futuras gerações. (BRUM; HILLIG, 2010).

O consumo do ser humano pressupõe seleção, aquisição e uso de bens e serviços. Segundo Saleh e Saleh (2012), o comportamento de quem consome deve envolver uma tomada de decisão, ajustando-se o que se tem para consumir e o que se pode consumir. $O$ padrão de responsabilidade sobre o consumo torna-se simples quando questionamos nossas motivações para o ato em si, isto é, quando nos conscientizamos da necessidade de usufruir ou não um bem que desejamos obter (BRUM; HILLIG, 2010).

Falar em consumidor responsável, de acordo com Saleh e Saleh (2012), não representa apenas uma ação final, mas um conjunto de ações que giram em torno desse conceito. Consumir para atender as próprias necessidades não parece questionável, mas para que seja um ato responsável, precisa considerar as possibilidades futuras de se continuar usufruindo esses recursos, sem que haja prejuízo para outros indivíduos (BRUM; HILLIG, 2010). Cumpre mencionar que, quando o gestor público define os critérios e as especificações dos bens e serviços a serem adquiridos em uma compra, sua atuação é a de um consumidor (COUTO; COELHO, 2015).

Os órgãos e autarquias públicas federais, dentre as quais a UFU está inserida, devem se posicionar em prol da sustentabilidade de suas ações e programas. E, considerando-se o vulto de recursos públicos envolvidos nas compras governamentais, vislumbrou-se a possibilidade de utilizar as licitações como instrumento de política pública ambiental (COUTO; COELHO, 2015).

Identificar as bases do consumo responsável para que este seja adotado como um valor cultural da humanidade tornou-se uma busca de grande relevância. Embora valores como a solidariedade e a preocupação com a preservação das espécies sejam defendidos por governantes e cidadãos conscientes, ainda há muito que aprimorar para que os modelos de desenvolvimento das sociedades atuais tornem-se ecologicamente corretos e sustentáveis. (BRUM; HILLIG, 2010, p. 117).

Segundo Saleh e Saleh (2012), entender a dinâmica de consumo em nossa sociedade moderna demanda a utilização de todas as ferramentas disponíveis em nosso universo escolar de forma articulada. Dessa forma, a política pública de compras sustentáveis passou a integrar um conjunto de políticas ligadas à sustentabilidade, buscando internalizar o conceito de logística sustentável na realidade das administrações públicas (COUTO; COELHO, 2015). 
Estratégias de combate ao consumo deveriam ser incentivadas de maneira mais sistemática em escolas e universidades para que gradativamente as sociedades conseguissem repensar seus espaços dentro da natureza, além de contribuírem para que valores mais saudáveis à nossa existência como espécie animal sejam praticados na promoção da satisfação da maioria. (BRUM; HILLIG, 2010, p. 124).

Consumidor educado para o consumo traz um bom retorno ao próprio sistema (SALEH; SALEH, 2012). Também os responsáveis por compras de uma organização, considerando-se o vulto das aquisições que fazem, são alvos da atenção comercial, de tal modo que exista legislação específica e esquemas de auditoria, com a finalidade de manter e acentuar a conduta ética de tais agentes (COUTO; COELHO, 2015). Pensar nossas ações como estratégia de resistência cultural a tudo o que for contrário à preservação ambiental é outro caminho para que seja incentivada a responsabilidade sobre o que consumimos (BRUM; HILLIG, 2010).

A adoção de critérios de sustentabilidade nas contratações governamentais, em nível federal, foi autorizada pela Instrução Normativa SLTI/MPOG no 1, de 19 de janeiro de 2010, a qual estabeleceu as diretrizes para a atuação do gestor público. Entretanto, a responsabilidade pela escolha de determinado bem, serviço ou obra continuou a cargo do gestor público, que atua de forma discricionária e, muitas vezes, não dispõe de ferramentas objetivas suficientes para poder valorar os ganhos ou danos ambientais de suas escolhas e, por conseguinte, para conduzir a implementação da política pública. (COUTO; COELHO, 2015, p. 521).

Destacamos que uma análise mais apurada relativa ao consumo responsável deve ir além do corriqueiro aspecto ambiental, devendo-se incluir, também, a publicidade, a saúde, a segurança, o direito e a ética (SALEH; SALEH, 2012). Assim, precisamos repensar nossas condutas como indivíduos sociais, buscando, por meio de uma ação conjunta de comprometimento com o bem estar e o futuro de toda a humanidade, uma mudança consciente das práticas nocivas ao ambiente natural e à adoção de um padrão de consumo (BRUM; HILLIG, 2010).

\section{Gestão ambiental em bibliotecas}

Nos últimos anos, surgiram diversas reflexões relacionadas às rápidas mudanças nas áreas científica, tecnológica, informacional, política, educacional e social, resultantes das inovações tecnológicas (FRANÇA; CARVALHO, 2015a). Segundo Cunha e outros (2014), a cada ano novos recursos e suportes passam a fazer parte das bibliotecas, transformando sua imagem de detentora dos livros em um centro de busca do saber, registrados nos mais diversos formatos, exigindo dos administradores, maior habilidade para reinventarem seus objetivos perante a demanda cada vez mais diversificada.

A evolução das tecnologias de informação e comunicação, de acordo com França e Carvalho (2015b), impulsionada pelo crescimento e democratização da rede mundial de computadores, pela ampliação da velocidade de conexão, pela mobilidade e pela convergência, a partir da década de 1960, facilitou o acesso ao conhecimento. Cunha e outros (2014) afirmam ser fundamental a construção de um plano de ação, contínuo e dinâmico, que registre as prioridades da unidade, indicando as etapas para se alcançar cada objetivo. Nesse sentido, o delineamento de um plano adequado é imprescindível para diminuir incertezas, minimizar riscos e ingerência de recursos.

As unidades informacionais têm vivenciado uma revolução interna, com a implementação de tecnologias que visam facilitar o acesso e a disseminação da informação, tornando-as mais 
dinâmicas (FRANÇA; CARVALHO, 2015b). Os objetivos a serem alcançados pelo esforço da equipe são definidos no planejamento e, de acordo com Cunha e outros (2014), para estabelecer as metas de uma unidade informacional, é essencial conhecer o perfil dos usuários, seus reais interesses e necessidades, bem como o plano de desenvolvimento e expansão da Instituição de Ensino Superior (IES).

Neste sentido, é fundamental que a missão, as metas e os objetivos da biblioteca estejam alinhados e sejam coerentes com o planejamento e a gestão da instituição de ensino superior à qual está vinculada, como uma das etapas para fortalecer sua importância e assegurar espaço nas políticas públicas educacionais do país. (FRANÇA; CARVALHO, 2015a, p. 17).

Esses indicadores servem de apoio para a definição das metas de uma organização, e o processo de gestão se simplifica à forma de conquista ou manutenção dessas metas. Estas devem ser desdobradas e alinhadas por toda a estrutura organizacional (CUNHA et al., 2014).

A mudança deve ser encarada como uma oportunidade de evolução, em que novos meios substituirão velhas práticas e novos bens e serviços serão implementados, com o objetivo de minimizar as diferenças quanto ao acesso à informação, construindo, na visão de França e Carvalho (2015b), uma sociedade informacional mais global e justa. Ações que corroboram a afirmação da International Federation of Library Associations and Institutions(IFLA, 2002), a respeito de que as bibliotecas e os serviços de informação podem ajudar a combater a desigualdade, por meio da disponibilização de novas tecnologias de acesso à informação, promovendo o desenvolvimento sustentável e o bem-estar dos povos.

\section{Questionamento norteador, a partir da literatura científica}

Falar em consumidor responsável não representa, para Saleh e Saleh (2012), apenas uma ação final, mas um conjunto de ações que giram em torno desse conceito. $\mathrm{O}$ consumismo da sociedade moderna tornou-se mais uma preocupação para os defensores de um ambiente saudável, de acordo com os preceitos de um desenvolvimento sustentável (BRUM; HILLIG, 2010).

A fim de acompanhar as novas tendências e aprimorar a qualidade dos serviços de informação e de tecnologia buscando a excelência, França e Carvalho (2015b) consideram que cabe aos gestores das bibliotecas universitárias buscarem novos modelos organizacionais, como implementação de planejamento tático e operacional, gestão participativa, parcerias e, principalmente, a gestão do conhecimento.

A mudança de paradigmas e ambientes advindos das novas tecnologias vem atraindo cada vez mais usuários para o conhecimento que é encontrado nestas unidades de informação e com esta demanda, cresce a preocupação em oferecer serviços relevantes em um curto espaço de tempo, evitando a obsolência da informação, o que exige um olhar crítico dos gestores e consequentemente a melhoria na gestão de qualidade dos serviços oferecidos (CUNHA et al., 2014, p. 4).

Para França e Carvalho (2015a), ao analisar a trajetória das bibliotecas universitárias, no âmbito das universidades federais, é preciso ter em mente o pensar e o refazer sobre si mesmas e, fundamentalmente, a extensão e o impacto dos serviços prestados tanto à comunidade universitária quanto à sociedade como um todo. Nesse sentido, fomos motivados a compreender de que maneira a adoção de práticas que viabilizem medidas para o consumo responsável, podem ser 
implementadas por meio de instrumentos de gestão ambiental nas bibliotecas da UFU. Dessa forma, foi feita uma análise dos projetos de extensão elaborados pelo SISBI, visando compreender como a sensibilização ambiental se dá ao longo do tempo e, por fim, descrevendo as possibilidades e desafios de sua abordagem.

\section{Material e Métodos}

O SISBI/UFU relaciona os três aspectos da sustentabilidade, a saber: econômico, social e ambiental, à realidade vivenciada em seu espaço físico.

$\mathrm{O}$ aspecto econômico é associado à produção, distribuição e consumo de bens e serviços; o social referente ao bem estar dos servidores e usuários; e, por fim, o aspecto ambiental, percebido como oportunidade de mitigar o impacto negativo gerado na organização. Atitudes sustentáveis:

implantação do Sistema de Gerenciamento e Aquisição de Material Informacional $(\mathrm{SIGAMI})^{7}$ totalmente automatizado, em parceria com o Centro de Tecnologia e Informação (CTI) da UFU;

publicação da resolução no 05/2011 do Conselho Diretor, que disciplina as condições e as rotinas de recebimento e de desfazimento de material informacional, no âmbito das Bibliotecas da UFU;

distribuição de canecas sustentáveis, em acrílico ou alumínio, durante a confraternização dos servidores, que ocorre anualmente;

possibilidade de envio por e-mail, através dos sistemas de autoatendimento, dos recibos de empréstimo e devolução;

disponibilização de scanners planetários para digitalização de pequenos trechos de obras do acervo com opção de salvar em dispositivo com entrada USB ou envio por e-mail;

desenvolvimento da Campanha pelo Silêncio e uso adequado das Bibliotecas do SISBI, minimizando ruídos nos espaços destinados a estudos das bibliotecas, considerado agente físico de risco ambiental, de acordo com Secretaria de Segurança e Saúde no Trabalho (BRASIL, 1994).

São realizadas também algumas ações em parceria com a Diretoria de Sustentabilidade Ambiental (DIRSU) ${ }^{8}$, da UFU que colaboram diretamente com a preservação ambiental, como: descarte de pilhas e baterias pelo público em recipientes instalados nas bibliotecas;

recolhimento de lâmpadas inservíveis e encaminhamento para local adequado, gerenciado pela DIRSU;

disponibilização de rascunho para usuários das bibliotecas, por meio do projeto Preservação de obras e mobiliários das Bibliotecas UFU ${ }^{9}$, onde a DIRSU atua no provimento de papel rascunho e negociação com empresas de reciclagem para recolhimento de resíduos.

O presente estudo é de abordagem qualitativa, agregado a recursos da abordagem quantitativa, de natureza aplicada e viés descritivo, a partir de levantamento bibliográfico (artigos de periódicos e livros), análise de documentos internos (estatística, relatórios entre outros), descrição das ações promovidas, consulta aos servidores do SISBI/UFU e da Diretoria de Sustentabilidade da UFU. Os procedimentos técnicos baseiam-se no estudo de caso, cujo objeto de estudo é o SISBI/UFU e suas ações de sustentabilidade ambiental.

\footnotetext{
$7 \quad$ Sistema único, integrado e modular para o gerenciamento dos processos de aquisição de material informacional das bibliotecas, que possibilita cadastro remoto nos sistemas de solicitação e doação, com acompanhamento das etapas de solicitação até o acervamento. Permite analisar as solicitações de forma eletrônica, sem necessidade de impressão das mesmas. Cf. http://www.sigami.ufu.br/

8 Cf. http://www.sustentavel.ufu.br/node/65

9 Projeto registrado em: PORTELA, Patrícia de Oliveira; RODRIGUES, Ana Paula Oliveira. (Coord.) Preservação de obras e mobiliários das Bibliotecas UFU: subprojeto disponibilização de rascunho. Uberlândia, 20I3.
} 


\section{Resultados e Discução}

O SISBI/UFU, desde 2011, adota algumas ações de sustentabilidade, que colaboram com a redução dos resíduos gerados pelas bibliotecas. Essas ações objetivam, em geral, a redução de custos, a promoção da Educação Ambiental e a diminuição do impacto ambiental. O Quadro 1 apresenta essas ações, com o respectivo ano de implantação e seus objetivos.

\section{Quadro 1 - Ações sustentáveis e seus objetivos}

\begin{tabular}{ccc}
\hline Ação & Ano & Resultado \\
\hline Implantação do SIGAMI. & 2011 & $\begin{array}{c}\text { Redução do consumo de papel em formato A4 } \\
\text { e de cartuchos para impressora. }\end{array}$ \\
\hline $\begin{array}{c}\text { Publicação da resolução no 05/2011 } \\
\text { do Conselho Diretor (CONDIR) que } \\
\text { disciplina as condições e as rotinas } \\
\text { de recebimento e de desfazimento } \\
\text { de material informacional no âmbito das } \\
\text { Bibliotecas da UFU. }\end{array}$ & 2011 & $\begin{array}{c}\text { Recebimento: evita o recebimento de material } \\
\text { indesejado, minimizando o acúmulo de resíduos. } \\
\text { Desfazimento: contribui economicamente com } \\
\text { outras instituições por meio da disponibilização } \\
\text { de doaçôes e também evita o acúmulo de } \\
\text { resíduos. }\end{array}$ \\
\hline $\begin{array}{c}\text { Recolhimento de lâmpadas fluorescentes. } \\
\text { Distribuição de canecas. }\end{array}$ & 2012 & Descarte correto de lâmpadas queimadas. \\
\hline $\begin{array}{c}\text { Envio de recibos de empréstimo por } \\
\text { e-mail. }\end{array}$ & 2013 & $\begin{array}{c}\text { Redução do consumo e da despesa com } \\
\text { aquisição de copos descartáveis. }\end{array}$ \\
\hline $\begin{array}{c}\text { Disponibilização de } \text { scanners para } \\
\text { reprografia e envio das imagens por } \\
\text { e-mail ou em USB }{ }^{10} \text {. }\end{array}$ & 2013 & $\begin{array}{c}\text { Reduça do consumo de papel e do gasto na do consumo de papel, economia } \\
\text { aquisição de bobinas. }\end{array}$ \\
\hline $\begin{array}{c}\text { financeira para o usuário e preservação do } \\
\text { material informacional. }\end{array}$ \\
\hline $\begin{array}{c}\text { Disponibilização de papel para rascunho. } \\
\text { Campanha pelo silêncio. }\end{array}$ & 2013 & $\begin{array}{c}\text { Destinação correta para o resíduo, preservação } \\
\text { do mobiliário, diminuição do consumo de } \\
\text { material e do tempo gasto na limpeza. }\end{array}$ \\
\hline Coletores de pilhas e baterias. & 2014 & Diminuição de ruído. \\
\hline
\end{tabular}

Fonte: Dos autores.

O SIGAMI foi desenvolvido pelo Sistema de Bibliotecas em parceria com o CTI da UFU. O sistema foi projetado para substituir os procedimentos de aquisição de material informacional que estavam obsoletos e não atendiam às atuais demandas, considerando principalmente o aumento expressivo da quantidade de solicitações/aquisições. Esse modelo funcionou de 1996 a 2010, período esse em que o processo de aquisição envolvia quatro sistemas, sendo: Solicitação Online, Base Aquisição, Pericon, Baixa e Transferência.

Em síntese, o processo ocorria da seguinte forma: os solicitantes, na grande maioria docentes, se dirigiam até as bibliotecas, efetuavam o cadastro no sistema de Solicitação Online e registravam suas solicitações. As chefias dos setores de Seleção e Aquisição (SESEL) e de Periódicos acessavam os pedidos, os imprimia e os distribuía aos servidores para analisarem cada solicitação. As anotações eram realizadas manualmente e, após conclusão, todas as solicitações eram digitadas, uma a uma, na Base Aquisição, exceto periódicos que eram digitados no Pericon ${ }^{10}$.

Esse formato não permitia o acompanhamento do fluxo pelos solicitantes, os quais para inteirar-se da situação, precisavam requisitar relatórios ao SESEL.

10 Sistema que gerenciava a aquisição e o controle das coleções de periódicos das bibliotecas da UFU. Universal Serial Bus. "Sistema de conexão universal." (CUNHA; CAVALCANTI, 2008, p. 372, tradução nossa) 
O sistema Baixa e Transferência era utilizado para gerenciar a baixa e a transferência de todo material informacional das bibliotecas da UFU.

Uma das maiores dificuldades em gerenciar a aquisição era o fato de os sistemas acima apresentados não serem integrados e modulares, dessa forma, o processo se tornava trabalhoso, oneroso, inacessível e ambientalmente inadequado, considerando principalmente a imensa quantidade de papel utilizada para imprimir todas as solicitações, bem como a perda de tempo ou re-serviço efetuado pelos servidores.

O Gráfico 1 demonstra que ocorreu uma redução no consumo de papel A4 após a implantação do SIGAMI.

\section{Gráfico 1 - Consumo folhas de papel A4 - 2011 a 2015}

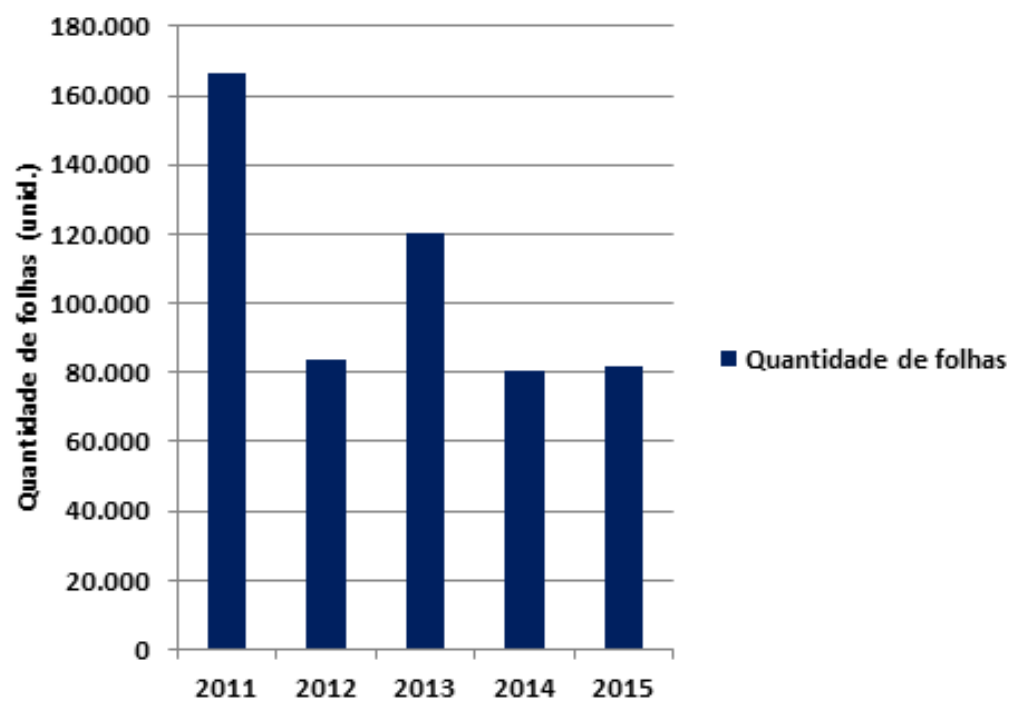

Fonte: Dos autores.

O aumento do consumo de papel A4 no ano de 2013, em relação ao ano anterior, justificase pela maior quantidade de dias úteis. As informações detalhadas sobre o consumo de papel A4 podem ser verificadas na Tabela 1 .

\section{Tabela 1 - Detalhamento do consumo de papel A4 - 2011-2015}

\begin{tabular}{ccccccc} 
Ano & $\begin{array}{c}\text { Quantidade } \\
\text { de pacotes - } \\
\text { 500fl cada }\end{array}$ & $\begin{array}{c}\text { Quantidade } \\
\text { de folhas }\end{array}$ & $\begin{array}{c}\text { Dias } \\
\text { úteis }\end{array}$ & $\begin{array}{c}\text { Uso } \\
\text { diário }\end{array}$ & $\begin{array}{c}\text { Número de } \\
\text { servidores }\end{array}$ & $\begin{array}{c}\text { Uso diário } \\
\text { por servidor }\end{array}$ \\
2011 & 333 & 166.500 & 204 & 816,2 & 104 & 7,8 \\
2012 & 168 & 84.000 & 214 & 392,5 & 113 & 3,5 \\
2013 & 240 & 120.000 & 275 & 436,4 & 118 & 3,7 \\
2014 & 161 & 80.500 & 207 & 388,9 & 111 & 3,5 \\
2015 & 164 & 82.000 & 173 & 474,0 & 113 & 4,2 \\
\hline
\end{tabular}

Fonte: Dos autores.

Em 2011, ocorreu a transição entre os módulos de gerenciamento de aquisição de material informacional, na qual os 4 sistemas acima citados foram substituídos pelo SIGAMI. 
A publicação da Resolução no 05/2011 do Conselho Diretor (CONDIR), que disciplina as condições e as rotinas de recebimento e de desfazimento de material informacional no âmbito das bibliotecas da UFU, é considerada uma importante ação de sustentabilidade, pois as bibliotecas deixaram de receber doações de maneira desordenada e, muitas vezes, inadequadas ao acervo. A normativa prevê a disponibilização das obras indesejadas a outras instituições devidamente credenciadas, ocasionando a redução de gastos, com aquisição de obras, pelas instituições receptoras, bem como minimizando a geração de resíduos no SISBI/UFU.

Em 2012, em parceria com a DIRSU, as lâmpadas inservíveis começaram a ser recolhidas e descartadas de forma adequada e ambientalmente correta. Anteriormente a esse ano, não havia logística reversa das lâmpadas fluorescentes por parte da Prefeitura Universitária. Não foi possível obter informações da quantidade de lâmpadas recolhidas no Sistema de Bibliotecas, porém em 2016, foram recolhidas aproximadamente 80 mil lâmpadas em toda a universidade, para destinação final ambientalmente adequada.

Em 2013, o SISBI/UFU implantou 5 ações de sustentabilidade, a saber:

distribuição de canecas;

envio de recibos de empréstimo por e-mail;

disponibilização de scanners para reprografia;

disponibilização de papel para rascunho e;

campanha pelo silêncio.

A distribuição de canecas foi uma iniciativa promovida em dezembro de 2013, durante a festa de confraternização do SISBI/UFU, em que todos os servidores receberam canecas em acrílico e, posteriormente, foi enviado um e-mail solicitando que utilizassem a caneca durante o horário de trabalho, no intuito de reduzir o consumo de copos descartáveis.

Sabe-se que os copos descartáveis são produzidos a partir de matéria prima não sustentável, o poliestireno (derivado do petróleo) e levam mais de 100 anos para se decompor na natureza. De acordo com a Universidade Federal de Ciências da Saúde de Porto Alegre (2009), o poliestireno, ao ser submetido ao calor, libera o estireno, monômero tóxico considerado cancerígeno.

A Tabela 2 apresenta o detalhamento do consumo de copos descartáveis pelo SISBI/UFU entre 2011 e 2015, com destaques para o aumento crescente até 2013 e a redução nos dois anos seguintes à distribuição de canecas, e para a redução do valor gasto com a aquisição dos materiais. Em 2013, ano de implantação, foi investido $\mathrm{R} \$ 1.294,30$ (mil duzentos e noventa e quatro reais e trinta centavos), em $2014, \mathrm{R} \$ 1.034,87$ (mil e trinta e quatro reais e oitenta e sete centavos) e em 2015 , $\mathrm{R} \$ 707,44$ (setecentos e sete reais e quarenta e quatro centavos), último ano analisado, resultando em 45,4\% de economia no orçamento do SISBI/UFU para esse fim.

Tabela 2 - Detalhamento do consumo de copos descartáveis - 2011-2015

\begin{tabular}{cccccccc}
\hline ANO & $\begin{array}{c}\text { Quant. de } \\
\text { copos }\end{array}$ & $\begin{array}{c}\text { Dias } \\
\text { úteis }\end{array}$ & $\begin{array}{c}\text { Uso } \\
\text { diário }\end{array}$ & $\begin{array}{c}\text { Quant. de } \\
\text { Servidores }\end{array}$ & $\begin{array}{c}\text { Uso } \\
\text { diário por } \\
\text { servidor }\end{array}$ & Valor gasto & $\begin{array}{c}\text { Valor } \\
\text { gasto por } \\
\text { servidor }\end{array}$ \\
\hline 2011 & 22.500 & 204 & 110,3 & 104 & 1,1 & $\mathrm{R} \$ 731,40$ & $\mathrm{R} \$ 7,03$ \\
2012 & 49.300 & 214 & 230,4 & 113 & 2 & $\mathrm{R} \$ 806,03$ & $\mathrm{R} \$ 7,13$ \\
2013 & 68.200 & 275 & 248 & 118 & 2,1 & $\mathrm{R} \$ 1.294,30$ & $\mathrm{R} \$ 10,97$ \\
2014 & 52.100 & 207 & 251,7 & 111 & 2,3 & $\mathrm{R} \$ 1.034,87$ & $\mathrm{R} \$ 9,32$ \\
2015 & 36.500 & 173 & 211 & 113 & 1,9 & $\mathrm{R} \$ 707,44$ & $\mathrm{R} \$ 6,26$ \\
\hline
\end{tabular}

Fonte: Dos autores. 
Com o propósito de se estabelecer como uma organização inovadora e sustentável, o SISBI/ UFU vem investindo em Tecnologias da Informação e Comunicação (TICs) que possam beneficiar os usuários e provocar o mínimo de agressão ao meio ambiente. De acordo com Schumpeter (1982), inovação é a substituição de formas antigas por novas formas de produzir e consumir. Nesse sentido, a aquisição de equipamentos de autoempréstimo possibilitou o envio de recibos por e-mail, proporcionando maior comodidade aos usuários, redução do consumo de papel e do gasto na aquisição de bobinas.

Os dados estatísticos referentes à economia de papel com o autoempréstimo, não podem ser apresentados em função da ausência de informações. Ainda assim, considerando a importância da ação para a diminuição do impacto ambiental, o SISBI/UFU, na substituição do software que gerencia as bibliotecas, requer que o novo sistema possibilite o envio de comprovantes de empréstimo e devolução aos usuários atendidos pessoalmente. Também foi solicitado ao fabricante dos equipamentos de autodevolução o ajuste para que este possibilite o envio de recibos por e-mail.

Em função dos vários problemas recorrentes com o serviço de reprografia prestado no interior da Biblioteca Central Santa Mônica, como: falta de qualidade, preço alto, falta de atendimento em alguns horários, entre outros, o SISBI/UFU, no final de 2013, iniciou o projeto piloto de disponibilização de scanner planetário. $\mathrm{O}$ equipamento possibilitou aos usuários a digitalização de partes de obras, de acordo com a lei de direitos autorais com opções de envio dos arquivos por e-mail ou gravados em dispositivos USB. A iniciativa proporcionou economia financeira ao usuário, liberação de espaço físico e, principalmente, a diminuição do impacto ambiental com a redução de cópias em papel.

As informações em relação aos escaneamentos podem ser apresentadas somente nos anos de 2014 e 2105. Tendo em vista que os equipamentos foram implantados no final do ano de 2013, não é possível informar os dados de reprografia nas dependências da biblioteca considerando que a empresa terceirizada que ofereceu o serviço não disponibiliza essa informação em termos quantitativos.

A Tabela 3 apresenta o detalhamento dos escaneamentos efetuados nos scanners da Biblioteca Central Santa Mônica nos anos de 2014 e 2015, com destaque para o aumento significativo do número de páginas escaneadas e para o valor $(\mathrm{R} \$)$ que seria gasto pelos usuários se as cópias fossem impressas por meio de copiadoras.

\section{Tabela 3 - Detalhamento dos escaneamentos - 2011-2015}

\begin{tabular}{cccccc}
\hline Ano & Quantidade & $\begin{array}{c}\text { Dias } \\
\text { úteis }\end{array}$ & $\begin{array}{c}\text { Cópias } \\
\text { diárias }\end{array}$ & $\begin{array}{c}\text { Valor } \\
\text { cópia }\end{array}$ & Valor total \\
\hline 2014 & 59366 & 207 & 286,8 & $\mathrm{R} \$ 0,10$ & $\mathrm{R} \$ 5.936,60$ \\
2015 & 86544 & 173 & 500,3 & $\mathrm{R} \$ 0,10$ & $\mathrm{R} \$ 8.654,40$ \\
\hline
\end{tabular}

Fonte: Dos autores.

O projeto de Preservação de obras e mobiliários das bibliotecas UFU: subprojeto disponibilização de rascunho ${ }^{11}$ foi instituído também em 2013. A ideia surgiu da necessidade de aumentar o tempo de vida útil dos mobiliários do ambiente de estudo das bibliotecas, tendo sido observado o uso das mesas como rascunho pelos alunos, principalmente nos períodos de avaliações acadêmicas. Uma das alternativas diagnosticadas foi a ampla disponibilização de papel rascunho nos ambientes de estudo. O objetivo do projeto foi alcançado, promovendo uma melhor utilização dos mobiliários II Projeto desenvolvido no SISBI/UFU: PORTELA, P. O.; RODRIGUES, A. P. O. (Coord.) Preservação de obras e mobiliários das Bibliotecas UFU: subprojeto disponibilização de rascunho. Uberlândia, 2013. 
pelos usuários. Ambientalmente, o resultado foi positivo e economicamente sustentável, pois o papel utilizado pelas unidades administrativas da UFU é aproveitado como rascunho, diminuindo a geração de resíduos, viabilizando a destinação correta do papel reutilizado às cooperativas de reciclagem, bem como a redução do tempo despendido na limpeza e a diminuição do gasto com produtos.

A Secretaria de Saúde e Segurança no Trabalho (BRASIL, 1994) classifica os ruídos como risco ambiental. Rodrigues (2009) considera o ruído como fator preponderante no conforto de ambientes internos, assinalando estudos que dizem respeito à interferência do ruído no ambiente escolar.

O estudante universitário, estimulado a desenvolver suas próprias atividades de aprendizado, utiliza cada vez mais as bibliotecas para este fim. Dessa forma, as bibliotecas precisam proporcionar aos usuários um ambiente de conforto acústico, que facilite a concentração e a capacidade de raciocínio. Na maioria das vezes, os próprios usuários são as principais fontes de ruídos, devido à comunicação entre eles. Para Hedge (2001), as conversas normais atingem entre 55 e 65 dB. Para normalizar, a NBR 10152 (ASSOCIAÇÃO BRASILEIRA DE NORMAS TÉCNICAS, 1992) estipula o nível de ruído para bibliotecas na faixa de 35 a $45 \mathrm{~dB}$. Nesse sentido, os aglomerados de pessoas, como tem sido nas bibliotecas da UFU, principalmente a Central Santa Mônica e Setorial Ituiutaba, chegam a causar incômodos. Para Kroemer e Grandjean (2005) o ruído interfere nas atividades de interpretação de informação.

Devido às reclamações registradas pelos usuários, por meio da ouvidoria da universidade, da autoavaliação institucional promovida pela Comissão Própria de Avaliação (CPA) e e-mails, sobre ruído excessivo nas bibliotecas, foi criada a Campanha "Asas do Silêncio." Implantado em 2013, como atitude atenuante para o problema instalado, o projeto Campanha pelo Silêncio e Uso Adequado das Bibliotecas do SISBI (FRANÇA; GOMES, 2016), que visava minimizar a poluição sonora e promover a educação dos usuários, teve seu objetivo alcançado. A partir desse plano, o principal desafio é dar continuidade às campanhas que propiciem a diminuição de ruídos e a utilização consciente dos espaços das bibliotecas.

A DIRSU da UFU, em 2014, instalou coletores de pilhas e baterias nas bibliotecas, cuja ação provoca o descarte correto destes dispositivos, evitando que os metais pesados, como cádmio, chumbo e mercúrio, utilizados na constituição dos mesmos, contaminem o meio ambiente e provoquem malefícios à saúde humana. A instalação dos coletores foi acompanhada pelo projeto de extensão processual e contínuo de caráter educativo, social, cultural, científico ou tecnológico, ação submetida no Sistema de Informação, de Extensão, Cultura e Assuntos Estudantis (SIEX) da UFU, registro $n^{\circ} 11558$, com objetivo específico e prazo determinado.

As ações adotadas pelo SISBI/UFU apresentaram resultados favoráveis que envolveram, principalmente, a redução do consumo de papel em função da implantação do SIGAMI, do envio de recibos por e-mail e disponibilização de scanners planetários.

A disponibilização de papel para rascunhos favoreceu a preservação do mobiliário, considerando que os usuários utilizavam os mesmos para fazer anotações. Essa ação também reduziu o tempo despendido na manutenção dos ambientes das bibliotecas, bem como a despesa com material de limpeza e água.

Entendendo que a produção do conhecimento intelectual exige ambiente silencioso, a Campanha "Asas do Silêncio" contribuiu para uma melhor conscientização dos usuários, referente à utilização dos espaços das bibliotecas da UFU.

O uso das canecas, em substituição aos copos plásticos usados em larga escala, reduziu a geração de resíduos e os gastos com a sua aquisição. Embora cada unidade seja de baixo custo, se for computada a quantidade diária utilizada, a economia é significativa. 
A publicação da resolução nº 05/2011 do CONDIR (UNIVERSIDADE FEDERAL DE UBERLANDIA, 2011), que disciplina as condições e as rotinas de recebimento e de desfazimento de material informacional, facilitou a reutilização do material por outras instituições e a não inserção no acervo de material indesejável recebido por doação, evitando o desperdício de tempo com processamento técnico.

Os coletores de pilhas e baterias e o recolhimento de lâmpadas usadas evitam que estes materiais sejam descartados de maneira inadequada, provocando a poluição e contaminação do meio ambiente.

Os resultados obtidos corroboram com Pereira (2014), considerando que o aumento do poder de consumo provoca prejuízos ao meio ambiente, sendo necessárias mudanças no modo de vida, sensibilizando culturalmente o consumo nas bibliotecas da UFU.

A adoção de tecnologias pode estar aliada ao meio ambiente na substituição de livros impressos por eletrônicos, no entanto ainda há preferência pelo impresso. Este cenário pode ser atribuído à queda no poder de compra da população brasileira, que afeta a aquisição de dispositivos móveis, ao baixo nível de letramento digital e à ausência de domínio de um segundo idioma. $\mathrm{O}$ investimento no livro impresso também é incentivado pelas políticas públicas, tendo em vista que o instrumento de avaliação de cursos do Ministério da Educação (MEC) privilegia a adoção de títulos impressos nas bibliografias dos projetos pedagógicos dos cursos.

\section{Considerações finais}

Esse conjunto de medidas de valorização de recursos inovadores, conhecimentos e atitudes, com o intuito promover a redução de custos e o impacto ambiental provocado pelo SISBI/UFU, são relevantes para que se propague a cultura da educação e preservação ambiental. Porém estão bastante aquém das possibilidades e das necessidades de tornar as bibliotecas da UFU locais de convívio sustentável, oferecendo produtos e serviços que evitem o impacto ambiental no presente e no futuro.

Esperamos que este trabalho inspire a gestão de outras bibliotecas a adotarem ações de sustentabilidade, bem como que o SISBI/UFU dê continuidade às ações já adotadas e implemente novos projetos que promovam o desenvolvimento sustentável.

\section{Referências}

ASSOCIAÇÃO BRASILEIRA DE NORMAS TÉCNICAS. NBR 10152: níveis de ruído para conforto acústico. Rio de Janeiro, 1992.

BRASIL. Ministério da Educação. Instrumento de avaliação de cursos de graduação presencial e a distância. Brasília, 2015. Disponível em: <http://download.inep.gov.br/ educacao_superior/avaliacao_cursos_graduacao/instrumentos/2015/instrumento_cursos_ graduacao_publicacao_agosto_2015.pdf >. Acesso em: 30 nov. 2016.

BRASIL. Ministério do Trabalho e Emprego. Secretaria de Segurança e Saúde no Trabalho. Portaria no 25, de dezembro de 1994. Diário Oficial da União, Brasília, DF, 30 dez. 1994. Seção 1, p. 21.280-21.282. Disponível em: <http://pesquisa.in.gov.br/ imprensa/jsp/visualiza/index.jsp?data=30/12/1994\&jornal=1\&pagina=240\&totalArqui vos $=336>$. Acesso em: 2 nov. 2016. 
BRUM, A. B. N.; HILLIG, C. Repensando o consumismo: uma reflexão sobre a necessidade de um consumo responsável. Revista Eletrônica em Gestão, Educação e Tecnologia Ambiental, Santa Maria, v. 1, n. 1, p. 115-128, 2010.

COUTO,H.L. G.; COELHO, C.. Fatores críticos no comportamento do gestor público responsável por compras sustentáveis: diferenças entre consumo individual e organizacional. Revista de Administração Pública, Rio de Janeiro, v. 49, n. 2, p. 519-543, 2015.

CUNHA, M. B; CAVALCANTI, C. R. O. USB. In: CUNHA, M. B; CAVALCANTI, C. R. O. Dicionário de biblioteconomia e arquivologia. Brasília, DF: Briquet de Lemos, 2008. p. 372

CUNHA, P. A. et al. Gestão orientada por resultados: o caso da Biblioteca da UFU. In: SEMINÁRIO NACIONAL DE BIBLIOTECAS UNIVERSITÁRIAS, 18., 2014, Belo Horizonte. Anais... Belo Horizonte: UFMG, 2014. p. 1- 20. Disponível em: $<$ https://www.academia.edu/9510590/Gest\%C3\%A3o orientada por resultados o caso da biblioteca da UFU $>$. Acesso em: 17 jan. 2017.

FRANÇA, M. N.; CARVALHO, A. M. G. Gestão em bibliotecas universitárias públicas: um enfoque tecnológico. In: ENCONTRO NACIONAL DE PESQUISA EM CIÊNCIA DA INFORMAÇÃO, 16., 2015a, João Pessoa. Anais... João Pessoa: ANCIB, 2015a. p. 1-21. Disponível em: <http://www.brapci.inf.br/index.php/article/ download/43969>. Acesso em: 17 jan. 2017.

FRANÇA, M. N.; CARVALHO, A. M. G. Sociedade da informação e biblioteca universitária: contribuições para a democratização do acesso ao conhecimento. In: ENCONTRO NACIONAL DE PESQUISA EM CIÊNCIA DA INFORMAÇÃO, 16., 2015b, João Pessoa. Anais... João Pessoa: ENANCIB, 2015b. p. 1-18. Disponível em: <http://www.ufpb.br/evento/index.php/enancib2015/enancib2015/paper/ viewFile/3012/1120>. Acesso em: 17 jan. 2017

FRANÇA, M. N.; GOMES, G. A. S. Sustentabilidade institucional: Campanha pelo Silêncio no Sistema de Bibliotecas da UFU.2016. Trabalho apresentado no XIX Seminário Nacional de Bibliotecas Universitárias, 2016.

HEDGE, A. Environmental ergonomics. In: KARWASKI, W. International encyclopedia of ergonomics and human factors. London: Tayloy \& Francis, 2001. v. 2, pt. 7, p. 995-999. Disponível em: <https://books.google.com.br/books?id=rs44QxArS4 UC\&pg=PA995\&lpg=PA995\&dq=Hedge,+ A.+ Environmental + ergonomics\&source $=b$ $\underline{180 t s=c s 6 Z d u z D 6 T \& s i g=Z D d e L t d-e a M i Y g o h U u D n-A n Y k y A \& h l=p t-B R \& s a=X \& v}$ ed=0ahUKEwjPoKTXv5XRAhXJS5AKHZWPDpEQ6AEIWjAJ\#v=onepage\&q=He dge\%2C\%20A.\%20Environmental\%20ergonomics\&f=false>. Acesso em: 17 jan. 2017. 
INTERNATIONAL FEDERATION OF LIBRARY ASSOCIATIONS AND INSTITUTIONS. Statement on libraries and sustainable development. 2002. Disponível em: <https://www.ifla.org/publications/statement-on-libraries-andsustainable-development>. Acesso em: 29 jan. 2017.

KROEMER, K.H. E.; GRANDJEAN, E. Manual de ergonomia: adaptando o trabalho ao homem. 5. ed. São Paulo: Bookman, 2005.

PEREIRA, F.Educação ambiental e interdisciplinaridade: avanços e retrocessos. Brazilian Geographical Journal: geosciences and humanities research medium, Ituiutaba, v. 5, n. 2, p. 575-594, 2014.

RODRIGUES, M. A. Condições de trabalho e conforto em bibliotecas do ensino superior. 2009.156 f. Tese (Mestrado) - Escola de Engenharia, Universidade do Minho, 2009. Disponível em: <http://repositorium.sdum.uminho.pt/bitstream/1822/10538/1/ tese_Matilde\%20Rodrigues_2009.pdf>.Acesso em: 19 dez. 2016.

SCHUMPETER, J. A. Teoria do desenvolvimento econômico. São Paulo: Abril Cultural, 1982.

SALEH, A. M.; SALEH, P. B. O. Consumo responsável: um passo além do aspecto ambiental. Educar em Revista, Curitiba, n. 44, p. 167-179, 2012.

SILVA, A. M. et al. Comportamentos ambientalmente responsáveis e sua relação com a educação ambiental. Revista de Gestão Ambiental e Sustentabilidade, São Paulo, v. 4, n. 1, p. 1-16, 2015.

UNIVERSIDADE FEDERAL DE CIÊNCIAS DA SAÚDE DE PORTO ALEGRE. Projeto de Desenvolvimento de Ações de Preservação Ambiental na UFCSPA. Porto Alegre, 2009. Disponível em: <http://ufcspa.edu.br/ufcspa/institucional/politicas_ gestaoambiental.pdf $>$. Acesso em: 4 dez. 2016.

UNIVERSIDADE FEDERAL DE UBERLÂNDIA. Reitoria. Resolução No 05/2011 do Conselho Diretor. Uberlândia: UFU, 2011. Disponível em: <http://www.bibliotecas. ufu.br/sites/bibliotecas.ufu.br/files/media/documento/resolucao_n05_2011_rotinas_ recebimento_desfazimento_de_matinformacional.pdf>.Acesso em: 4 dez. 2016.

UNIVERSIDADE FEDERAL DE UBERLÂNDIA. Sistema de Bibliotecas. Visão. Uberlândia, 2016. Disponível em: $<$ https://www.bibliotecas.ufu.br/institucional $>$. Acesso em: 28 abr. 2016. 